\title{
СТАРЕНИЕ И ДОЛГОЛЕТИЕ
}

() О.И. Большакова, А.А. Жук,

Д.И. Родин, Г.А. Кислик,

\section{С.В. Саранцева}

Федеральное государственное бюджетное учреждение СанктПетербургский институт ядерной физики им. Б. П. Константинова

\section{ஜ Исследовано влияние} экспрессии гена белка предшественника амилоида ( $A P P)$ на популяции холинергических и дофаминергических нейронов. Количество холинергических нейронов, измеренное по уровню общей флуоресценции в мозге, было одинаковым в контрольной и опытных линиях в первые дни жизни мух, и снижалось в линиях, экспрессирующих АРP с возрастом. Количество дофаминергических нейронов в линиях, экспрессирующих $\boldsymbol{A P P}$, было достоверно ниже, начиная с 15-го дня. Нейродегенерация сопровождалась уменьшением способности мух к обучению и запоминанию как для линий, экспрессирующих только АPP (APP-Swedish), так и для линий с образованием амилоидного пептида бета (Aß).

\section{\& Ключевые слова: болезнь} Альцгеймера; Drosophila melanogaster; нейродегенерация; амилоидный пептид бета; холинергические нейроны; дофаминергические нейроны.

Поступила в редакцию 14.09.2012 Принята к публикации 19.12.2012
УДК 577.214+595.773.4]+612.82

\section{ВЛИЯНИЕ ГИПЕРЭКСПРЕССИИ ГЕНА АРР ЧЕЛОВЕКА НА ХОЛИНЕРГИЧЕСКИЕ И ДОФАМИНЕРГИЧЕСКИЕ HЕЙРOHЫ DROSOPHILA MELANOGASTER}

Болезнь Альцгеймера (БА) — нейродегенеративное заболевание, которое является основной причиной деменции людей в пожилом и старческом возрасте. Согласно одной из гипотез развития БА, главную роль в проявлении клинических симптомов заболевания играет селективная гибель холинергических нейронов ( более 70 \%) преимущественно в области базальных ядер Мейнерта (Whitehouse et al., 1982), которые являются одним из основных источников холинергической иннервации коры больших полушарий мозга (Mesulam et al., 1983). Ряд исследователей приводят данные о нарушениях при БА и в других нейротрансмиттерных системах - дофаминовой, серотониновой, глутаматной, адреналиновой (Chen et al., 2011 ; Schaeffer et al., 2008; Sun et al., 2012). Однако причины нейродегенеративных изменений при БА остаются малопонятными.

Согласно гипотезе амилоидного каскада, которая в настоящее время является центральной гипотезой патогенеза БА, накопление в ткани мозга растворимых и нерастворимых форм А $\beta$ запускает цепочку патологических реакций, приводящих к гибели нейронов и, в конечном итоге, к развитию деменции (Hardy, Selkoe, 2002). В свою очередь, А $\beta$ является результатом протеолитического процессинга $\beta$ - и $\boldsymbol{\gamma}$-секретазами большого трансмембранного белка APP (Thinakaran et al., 2008), мутации в гене которого приводят к развитию семейных форм БА.

Однако целый ряд исследований свидетельствует о наличии альтернативных путей развития этого заболевания (Saura et al, 2004; Bonda et al., 2009; Mohandas et al., 2009; Pimplikar et al., 2010). Также было показано, что наряду с $A \beta$ в нейродегенерации могут принимать участие как полноразмерный APP, так и другие фрагменты, образующиеся в результате его процессинга (Kim et al., 2003; Stokin et al., 2008; Słomnicki et al., 2008; Sarantseva et al., 2009).

В большинстве моделей БА, созданных на млекопитающих, гиперэкспрессия $A P P$ приводит к увеличению уровня $\mathrm{A} \beta$ и накоплению олигомеров $\mathrm{A} \beta$, которые могут вызывать нейродегенерацию и дефицит когнитивных функций (Walsh, Selkoe, 2004). Хотя гиперэкспрессия APP и отложения А $\beta$ у трансгенных животных не полностью воспроизводят все аспекты БА, эти модели создают реальные возможности для изучения нейропатологии, связанной с БА. В частности, они помогают объяснить вклад АРP и А $\beta$ в патогенез семейных форм БА. И в этой связи Drosophila melanogaster имеет ряд преимуществ перед другими модельными объектами, поскольку позволяет дифференцировать эффекты APP и А $\beta$. Во-первых, ген APPL, ортолог APP у Drosophila, не содержит региона, кодирующего Аß. Во-вторых, у Drosophila представлены все компоненты белкового комплекса, ответственного за активность $\gamma$-секретазы, но отсутствует или является необычайно низкой активность $\beta$-секретазы (BACE). Поэтому для генерации $A \beta$ необходимы двойные трансгены, экспрессирующие бета-секретазу и полноразмерный ген $A P P$ челове- 
ка. Это обстоятельство дает возможность разделения эффектов АРР и А $\beta$. Достаточно лишь сравнить линию, несущую только трансген $A P P$, с линией, несущей два трансгена - $A P P$ и $B A C E$. Следует сказать, что разделение цитотоксических эффектов $\mathrm{A} \beta$ и $\mathrm{APP}$ позволяет ответить на вопрос о природе основных патогенетических механизмов БА и имеет первостепенное значение для выработки подходов в терапевтическом лечении БА.

Целью данной работы явилось исследование влияния экспрессии $A P P$ человека на популяции холинергических и дофаминергических нейронов у трансгенных линий Drosophila melanogaster, а также на способность трансгенных мух к обучению и запоминанию.

\section{МАТЕРИАЛЫ И МЕТОДЫ}

Линии Drosophila melanogaster, использованнье в работе

Для анализа дегенерации холинергических и дофаминергических нейронов мы использовали следующие линии: $U A S-A P P$ (содержит ген $A P P$ человека, далее в тексте APP); UAS-APP-Swedish (содержит ген APP человека с мутацией Swedish, приводящей к наследственной форме БА, далее в тексте APP-Sw); BACE (содержит ген бета-секретазы человека, далее в тексте $B A C E)$. Экспрессия трансгенов была проведена в системе UAS-GAL4 (Brand, Perrimon, 1993). В качестве активаторов транскрипции был использован драйвер GAL4-Cha (линия GAL4-Cha-UAS-GFP), обеспечивающий экспрессию генов, находящихся под управлением $U A S$, в холинергических нейронах (далее в тексте Cha), и драйвер ple-GAL4 (экспрессия в дофаминергических нейронах, далее в тексте ple). Для анализа дофаминергических нейронов использовали линию $U A S-C D 8-G F P$, (далее в тексте $C D 8$ ). Линии были получены из коллекции Drosophila Bloomington Stock Center. Во время проведения экспериментов мухи содержались на стандартной дрожжевой среде при температуре $29{ }^{\circ} \mathrm{C}$ при 12 часовом световом дне.

Приготовление образцьов для конфокальной микроскопии

Для приготовления образцов для конфокальной микроскопии мух помещали в фосфатный буфер, головы отделяли от тела, обрабатывали октаном и фиксировали в растворе $4 \%$-го параформальдегида в фосфатном буфере 7 минут при комнатной температуре. После фиксации промывали в фосфатном буфере и выделяли мозг, который помещали на предметные стекла в раствор фосфатного буфера с глицерином в соотношении $1: 1$.

Конфокальная микроскопия и анализ изображений

Конфокальная микроскопия была проведена с помощью микроскопа Leica TCS SP5 со встроенным 35-мBт аргонным лазером. Сканирование всех образцов проводилось при одинаковых настройках сканирования. Препараты анализировали при длине волны $\lambda=488$ нм.
Толщина оптических срезов при сканировании составляла $1 \mu$ м. Оценка интенсивности флуоресценции при анализе холинергических нейронов была проведена на микрофотографиях конфокальных срезов в программе ImageJ (version 1.38a for Windows). Подсчет дофаминергических нейронов был проведен на микрофотографиях конфокальных срезов в программе ImageJ (version 1.38a for Windows), согласно методике из статьи Ботелла с соавт. (Botella et al., 2008). Обрабатывали по шесть образцов мозга из трех повторностей каждой возрастной группы каждого скрещивания.

Анализ обучаемости и памяти трансгенных мух

Тест на обучение и память к распознаванию запахов проводился по методике, предложенной Талли и Квинном (Tully, Quinn, 1985). Тест основан на способности Drosophila к выработке условных рефлексов. Во время обучения 50-70 мух помещали в тестовую трубку, покрытую изнутри металлической сеткой. Через трубку насосом непрерывно прокачивался воздух. Использовали два вещества с сильным запахом - 3'-октанол и 4-метилциклогексанол. В течение 1 минуты вместе с током воздуха подавали одно вещество, и в его присутствии мухи получали слабые удары электрическим током. Далее в течение 1 минуты подавали воздух без вещества и электрошока (время «отдыха»), а затем в течение 1 минуты второе пахнущее вещество, но уже без электрошока. Сразу же после этой процедуры измеряли способность к обучению: мух на 2 минуты помещали в Т-образную трубку («точку выбора») между встречными течениями двух запахов. Через 1 час с помощью такой же процедуры проверяли способность мух к запоминанию. Индексы обучения и памяти вычисляли следующим образом: из числа мух, сделавших правильный выбор, вычитали число мух, сделавших неправильный выбор. Полученную разность делили на общее число мух и умножали на 100.

Статистическая обработка результатов

Достоверность различий между контролем и вариантами эксперимента определяли с помощью метода однофакторного дисперсионного анализа (one-way ANOVA) и теста множественных сравнений Тьюки-Крамера (Tukye-Kramer test) программы Kyplot. Статистически значимыми считали различия при $\mathrm{p}<0,05$.

\section{РЕЗУЛЬТАТЫ}

Анализ нейродегенерациии холинергических нейронов

Анализ холинергических нейронов проводили у потомков от скрещиваний мух линии Cha и мух линий $A P P$, $A P P-S$ ш и $B A C E ; A P P-S w$ на $3-5,15-17$ и 29-30-й дни их жизни методом конфокальной микроскопии. Ацетилхолин является основным медиатором возбуждения в центральных синапсах Drosophila, поэтому в контрольной линии Cha наблюдались многочисленные сигналы флуоресценции большой плотности по всему мозгу, 
а также в глазных долях. В этом случае оказалось невозможным провести прямой подсчет холинергических нейронов в мозге Drosophila как вручную, так и в автоматическом режиме. Таким образом, для оценки общего количества холинергических нейронов мы использовали анализ уровня общей флуоресценции в мозге.

На рисунке 1 представлены фотографии мозга Drosophila melanogaster с экспрессией APP в холинергических нейронах в зависимости от возраста и генотипа. В образцах мозга мух всех линий свечение наблюдалось в одних и тех же структурах: в антеннальных долях, центральном комплексе, промежуточных нейронах рядом с антеннальными долями, грибовидных телах и клетках Кеньона. Эти отделы мозга отвечают у Drosophila за восприятие внешних сигналов, локомоторные функции, обучение и память. Уровень флуоресценции к 30-му дню жизни мух был понижен во всех структурах. Однако если в контроле у мух $C h a /+$ наибольшее снижение уровня флуоресценции наблюдалось в центральном комплексе и промежуточных нейронах рядом с антеннальными долями, то в опытных образцах с экспрессией $A P P$ и $A P P$ $S w$ по отдельности или с экспрессией $B A C E$ и $A P P-S w$
3-5 дней

A

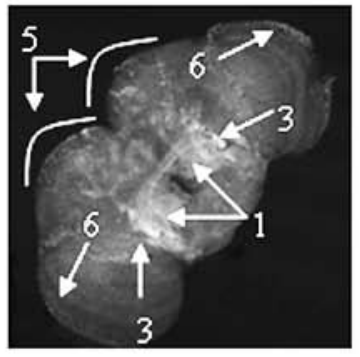

B

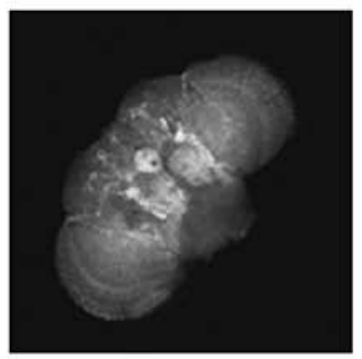

C

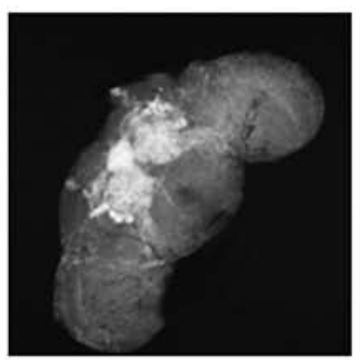

D

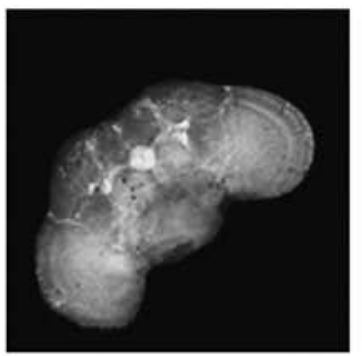

$14-16$ дней
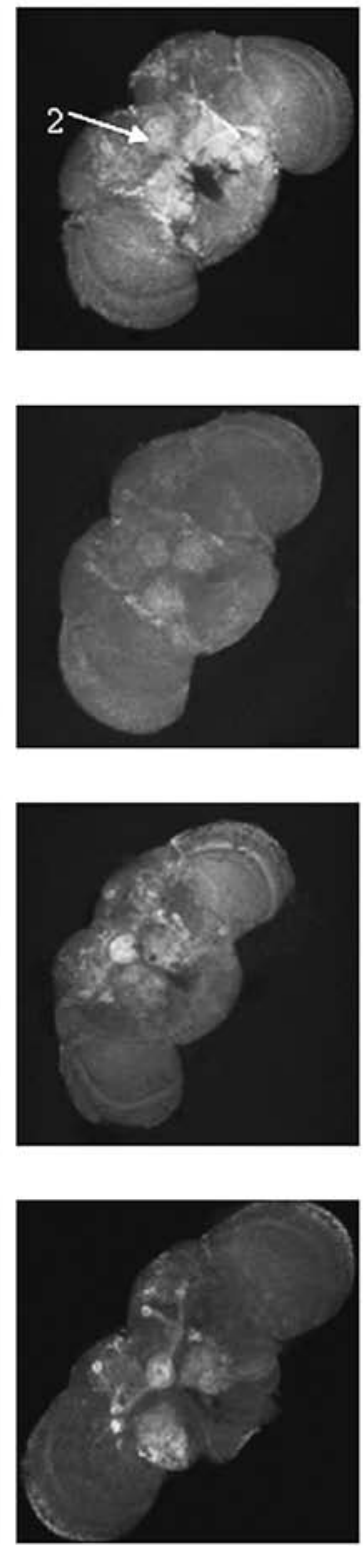

$28-30$ дней
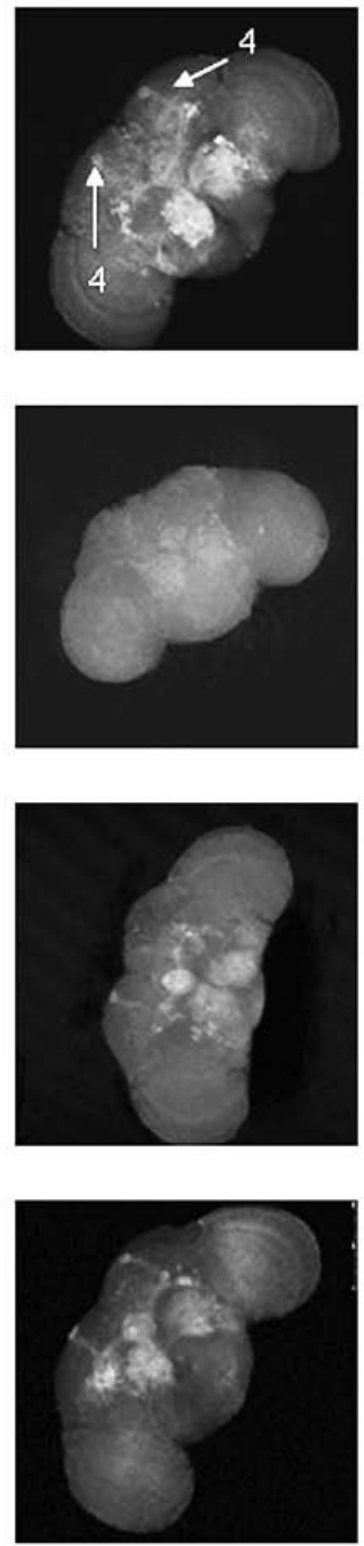

Рис. 1. Фотографии мозга Drosophila melanogaster с экспрессией $A P P$ в холинергических нейронах в зависимости от возраста и генотипа. 1 - антеннальные доли, 2 - центральный комплекс, 3 - промежуточные нейроны, 4 - аксоны грибовидных тел, 5 - внутренние нейроны грибовидных тел (клетки Кеньона), 6 - нейроны ламины (lamina). A - Cha $/+, \mathrm{B}-\mathrm{Cha} / \mathrm{APP}$ $\mathrm{C}-\mathrm{Cha} /+; A P P-S w /+, \mathrm{D}-\mathrm{Cha} / \mathrm{BACE} ; A P P-S w /+$ 

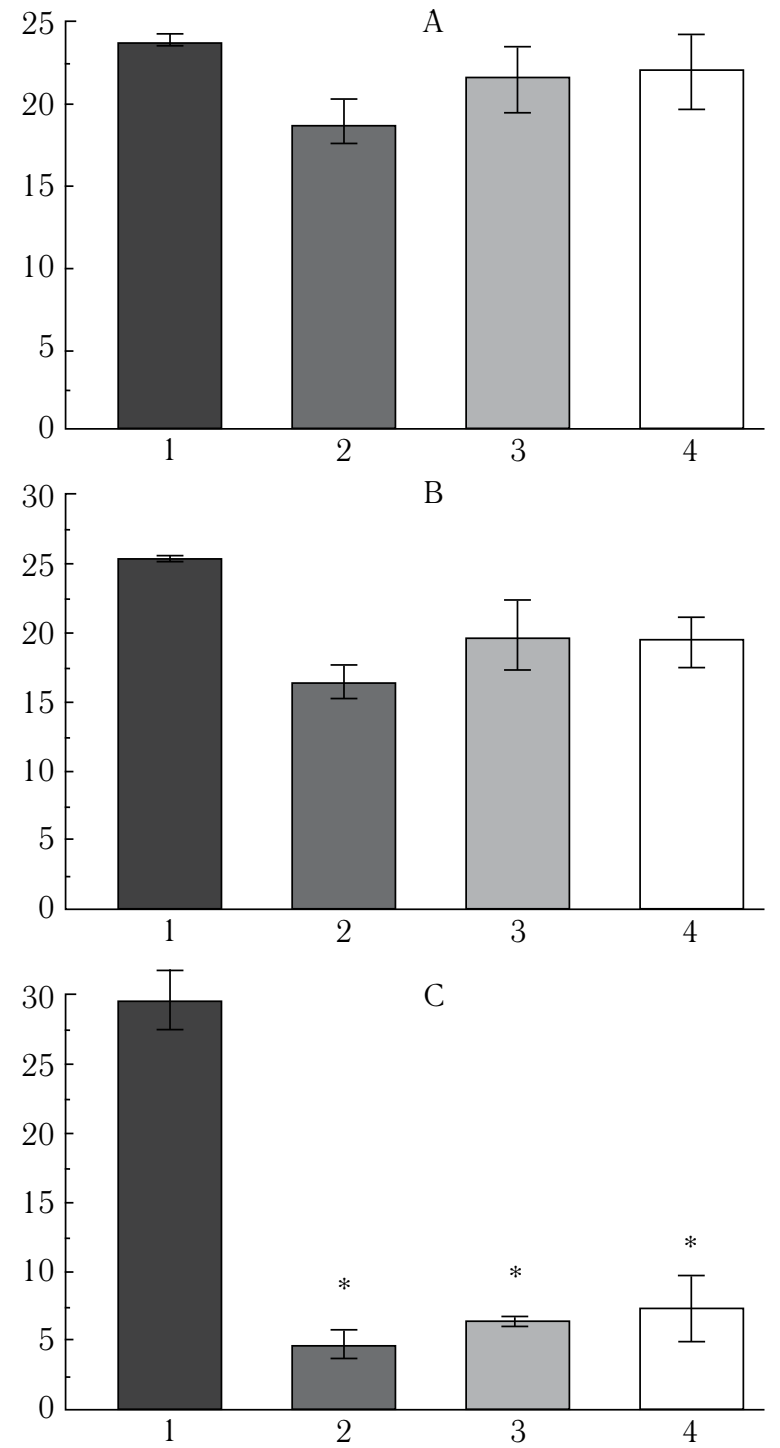

Рис. 2. Влияние экспрессии генов $A P P$ и $B A C E$ на холинергические нейроны Drosophila. А. Относительная флуоресценция образцов мозга 3-5-дневных мух. В. Относительная флуоресценция образцов мозга 15-17 дневных мух. С. Относительная флуоресценция образцов мозга 27-30-дневных мух. 1 - Cha/+, 2 - Cha/APP $3-$ Cha/+;APP-Sw/+, 4-Cha/BACE;APP-Sw/+. * отмечены статистически значимые результаты $(\mathrm{p}<0,05)$

одновременно, этот показатель в большей степени был снижен в антеннальных долях и грибовидных телах.

На рисунке 2 представлены в форме диаграмм средние численные значения относительной интенсивности флуоресценции на $3-5,15-17$ и $27-30$ дни в контрольной линии $C h a /+$, линиях с экспрессией $A P P, A P P-S w$ и одновременной экспрессией $B A C E$. Как видно из полученных данных, уровень флуоресценции на 3-5-й день одинаков в контрольной и опытных линиях, в то время, как на 15-17-й день он понижен в линиях, экспрессирующих $A P P$ и резко снижается в мозге мух этих линий на $27-30$-й день. В контрольной линии относительный уровень флуоресценции во время опыта оставался практически неизменным. Мы не наблюдали статистически достоверной разницы между линиями с экспрессией полноразмерного $A P P$ и линией, где образовывался $A \beta$.

Анализ нейродегенерациии дофаминергических нейронов

Для визуализации дофаминергических нейронов методом конфокальной микроскопии мы использовали трансгенную линию $C D 8$, мембраны нервных клеток которой мечены зеленым флуоресцентным белком. На рисунке 3 представлены фотографии мозга Drosophila melanogaster с экспрессией APP в зависимости от возраста и генотипа. На фотографиях видно, что дофаминергические нейроны в мозге Drosophila собраны в небольшие билатеральные кластеры, расположенные по всему мозгу (рис. 3).

Мы провели автоматический подсчет дофаминергических нейронов на $3-5,15-17$ и 27-30-й дни, используя программy ImageJ. Полученные нами результаты представлены на рисунке 4. Қак видно из рисунка, количество дофаминергических нейронов статистически достоверно снижается в линиях, экспрессирующих АPP, начиная с 1517 -го дня. В то же время в контрольной линии количество дофаминергических нейронов остается на одном и том же уровне в течение всего опыта. Мы не наблюдали статистически достоверной разницы между линиями, в которых гибель нейронов вызвана экспрессией полноразмерного $A P P$ и линиями с образованием $A \beta$. Таким образом, полученные нами результаты указывают на то, что как и в случае с холинергическими нейронами, гибель дофаминергических нейронов, вызываемая экспрессией $A P P$, может происходить в мозге Drosophila в отсутствии образования А $\beta$.

Анализ памяти и способности к обучению

Исследования нейродегенеративных изменений при БА показывают, что у пациентов с БА степень утраты холинергических нейронов коррелирует со степенью когнитивной дисфункции (Francis et al, 1999, Kar et al, 2004). Параллельно оценке состояния холинергических и дофаминергических нейронов, мы провели анализ способности мух к обучению и запоминанию на 2-5-й и 15-й дни их жизни. Способность к обучению в используемом нами тесте оценивалась индексом обучения, а индекс запоминания свидетельствавал о памяти животных. В таблицах 1 и 2 представлены результаты тестов на способность мух к обучению и запоминанию. Из таблиц следует, что способность животных к обучению и запоминанию достоверно снижена по сравнению с контролем уже со второго дня жизни мух. Это показано как для линий, экспрессирующих только $A P P(A P P-S w)$, так и для линий с образованием $\mathrm{A} \beta$.

\section{ОБСУЖДЕНИЕ}

Уже на ранней стадии заболевания у больных БА наблюдается ослабление функций холинергической системы 
(Whitehouse et al., 1982), уменьшение на 50-90\% уровня ацетилхолинтрансферазы, основного фермента участвующего в синтезе ацетилхолина (ChAT) (Davies, 1979), а также снижение плотности никотиновых ацетилхолиновых рецепторов (нАцХР) (Guan et al. 2000). Все эти изменения, как полагают, обусловлены гибелью холинергических нейронов в определенных отделах мозга. В то же время показано, что некоторые типы нАцХР задействованы в регуляции дофаминергической системы (Perry et al., 1995; Exley et al., 2012). Снижение их плотности при БА может обуславливать нейродегенерацию дофаминовых нейронов. С потерей дофаминергических нейронов в области черной субстанции связывают проявление симптомов паркинсонизма, которые наблюдаются у более, чем трети больных БА (Kazee et al., 1995; Burns et al., 2005). Предполагается, что важную роль в гибели и дисфункции холинергических и дофаминергических нейронов при БА играет образование $\mathrm{A} \beta$ (Perez et al., 2005).

$\mathrm{B}$ настоящей работе мы исследовали роль гена $A P P$ в развитии нейродегенерации на трансгенных линиях
3-5 дней
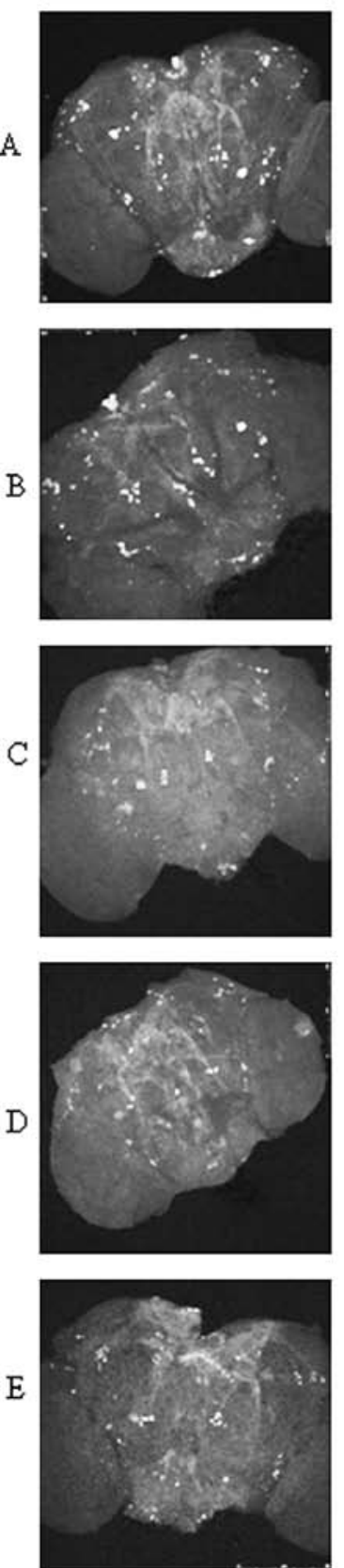

15-17 дней
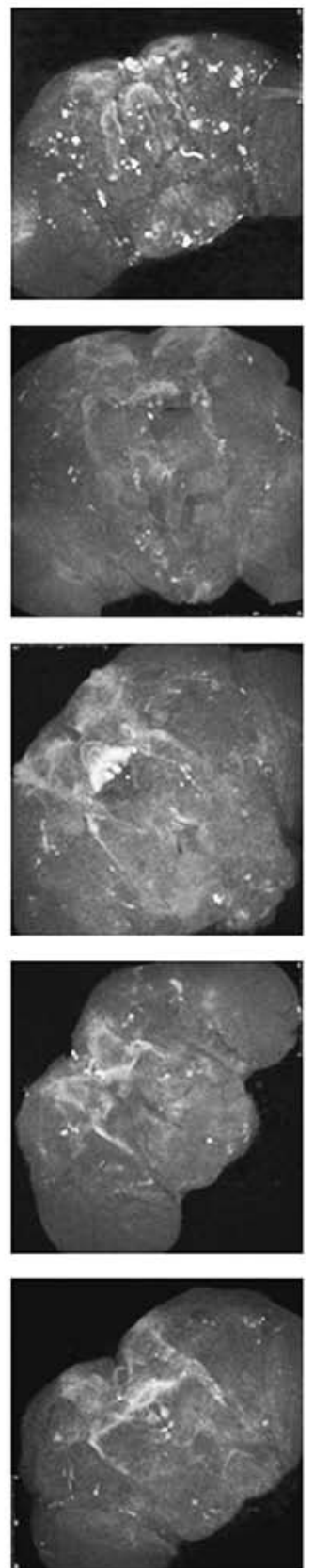

27-30 дней
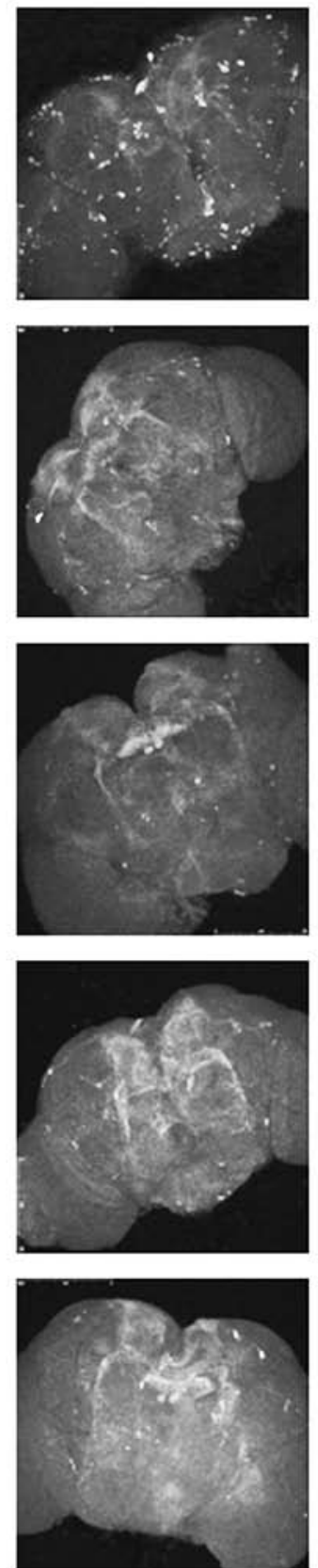

Рис. 3. Фотографии мозга Drosophila melanogaster с экспрессией $A P P$ в дофаминергических нейронах в зависимости от возраста и генотипа. A - CD8/+; ple/+, B - CD8/+;APP/+; ple/+, C - CD8/+; APP/BACE; ple/+, D - CD8/+;APP-Sw/ ple, $\mathrm{E}-C D 8 /+; B A C E /+; A P P-S w / p l e$ 


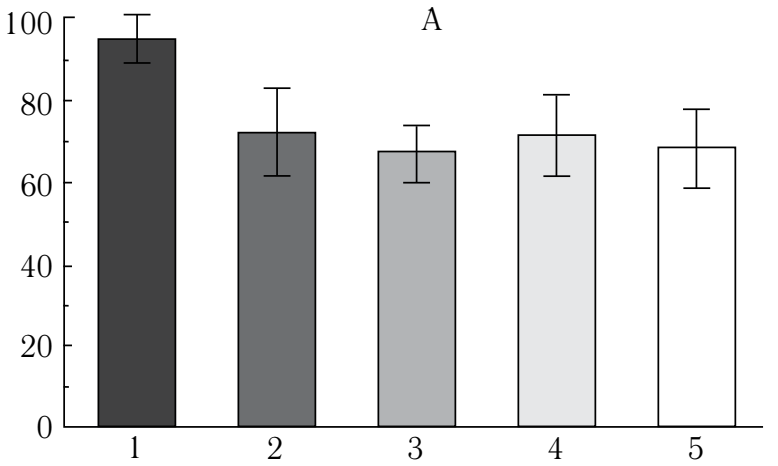

B

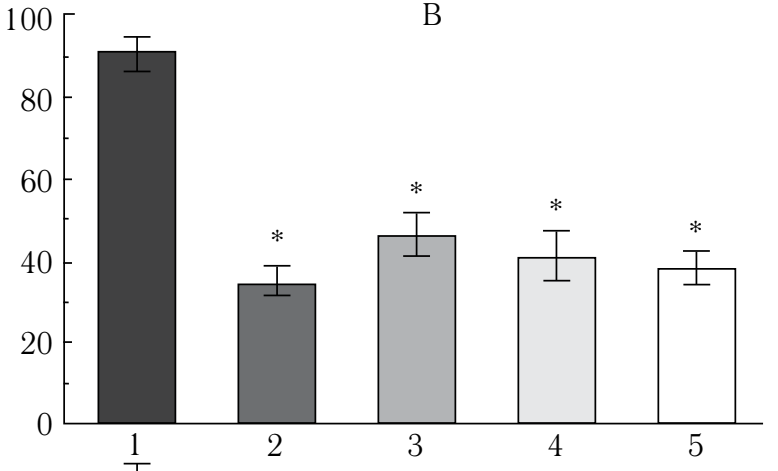

C

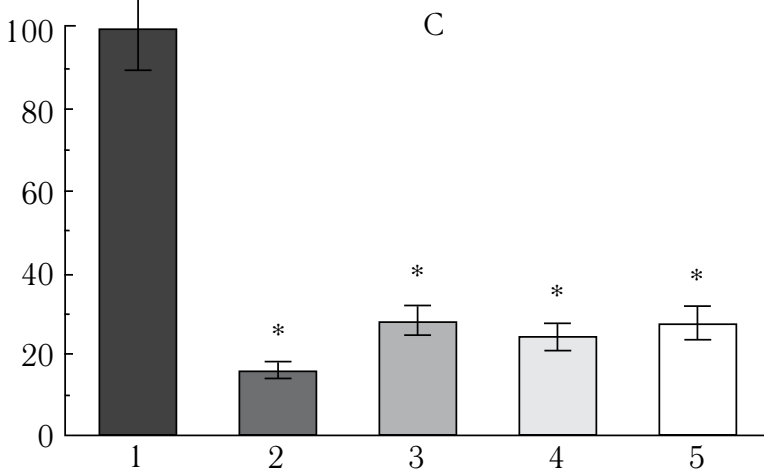

Рис. 4. Влияние экспрессии генов $A P P$ и $B A C E$ на дофаминергические нейроны Drosophila. Зависимость от возраста и генотипа. А - Количество дофаминергических нейронов в мозге 5-7-дневных мух. В - Количество дофаминергических нейронов в мозге 15-17-дневных мух. С - Количество дофаминергических нейронов в мозге 27-30-дневных мух. $1-C D 8 /+;$ ple $/+.2-C D 8 /+; A P P /+;$ ple $/+.3-$ CD8/+; APP/BACE;ple/+. $4-C D 8 /+; A P P-S w / p l e$. 5 - CD8/+; BACE/+; APP-Sw/ple. * отмечены статистически значимые результаты $(\mathrm{p}<0,05)$

Drosophila melanogaster, позволяющих дискриминировать эффекты экзогенного белка APP и непосредственно А $\beta$. Экспрессия $A P P$ или $A P P-S w$, а также совместная экспресии $A P P(A P P-S w)$ и $B A C E$ приводила к нейродегенерации холинергических (на 30-й день жизни) и дофаминергических (на 15-й день жизни) нейронов в мозге животных. Гибель нейронов особенно была заметна в линиях с экспрессией полноразмерного АРP. Образование А $\beta$ также приводило к развитию
Таблиц̧а 1

Влияние экспрессии генов $A P P$ и $B A C E$ на обучаемость трансгенных мух

\begin{tabular}{|c|c|c|}
\hline$\underbrace{\text { Возраст }}_{\text {Генотип }}$ & 3-5 дней & 15-17 дней \\
\hline Cha/+* & $15,6 \pm 1,8$ & $18,1 \pm 0,5$ \\
\hline Cha/APP & $4,8 \pm 2,6$ & $2,6 \pm 1,1$ \\
\hline Cha/+;APP-Sw/+ & $5,6 \pm 1,04$ & $3,4 \pm 1,4$ \\
\hline Cha/BACE;APP-Sw/+ & $0,1 \pm 1,23$ & $2,5 \pm 0,6$ \\
\hline ple/+* & $12,2 \pm 0,2$ & $15,5 \pm 2,2$ \\
\hline APP/+;ple/+, & $3,2,0 \pm 0,6$ & $1,8 \pm 0,9$ \\
\hline APP/BACE;ple/+ & $1,0 \pm 1,1$ & $1,5 \pm 0,6$ \\
\hline APP-Sw/ple & $3,9 \pm 1,3$ & $4,3 \pm 1,1$ \\
\hline BACE/+;APP-Sw/ple & $0,25 \pm 3,5$ & $4,0 \pm 1,7$ \\
\hline \multicolumn{3}{|c|}{$\begin{array}{l}\text { В таблице показан индекс обучения, расчет которого описан в } \\
\text { «Материалах и методах». * отмечены контрольные линии. Ста- } \\
\text { тистический анализ проведен с помощью программы one-way } \\
\text { ANOVA и теста Тьюки-Крамера (Tukey-Kramer multiple com- } \\
\text { parison post hoc test). Статистически значимыми считались раз- } \\
\text { личия при p <0,05. Жирным шрифтом выделены статистически } \\
\text { значимые различия по сравнению с контрольными линиями }\end{array}$} \\
\hline
\end{tabular}

таблиц̧а 2

Влияние экспрессии генов $A P P$ и $B A C E$ на память трансгенных мух

\begin{tabular}{|c|c|c|}
\hline$\overbrace{\text { Генотип }}^{\text {Возраст }}$ & $3-5$ дней & 15-17 дней \\
\hline Cha/ ${ }^{*}$ & $18,6 \pm 2,4$ & $16,8 \pm 0,8$ \\
\hline Cha/APP & $4,1 \pm 2,4$ & $0,8 \pm 0,2$ \\
\hline Cha/+;APP-Sw/+ & $8,5 \pm 1,3$ & $2,6 \pm 1,2$ \\
\hline Cha/BACE;APP-Sw/+ & $4,4 \pm 2,5$ & $2,8 \pm 1,3$ \\
\hline ple $/+*$ & $11,3 \pm 2,2$ & $12,6 \pm 1,3$ \\
\hline$A P P /+; p l e /+$, & $6,0 \pm 0,9$ & $1,5 \pm 0,6$ \\
\hline APP/BACE;ple/+ & $2,0 \pm 6,6$ & $1,3 \pm 0,9$ \\
\hline APP-Sw/ple & $1,25 \pm 4,0$ & $1,4 \pm 0,8$ \\
\hline BACE/+;APP-Sw/ple & $1,4 \pm 1,7$ & $1,6 \pm 0,7$ \\
\hline
\end{tabular}

В таблице показан индекс запоминания, расчет которого описан в «Материалах и методах». * отмечены контрольные линии. Статистический анализ проведен с помощью программы one-way ANOVA и теста Тьюки-Крамера (Tukey-Kramer multiple comparison post hoc test). Статистически значимыми считались различия при $p<0,05$. Жирным шрифтом выделены статистически значимые различия по сравнению с контрольными линиями

нейродегенерации, но ее уровень статистически достоверно не отличался от такого в линиях с экспрессией $A P P(A P P-S w)$. Уменьшение количества холинергических и дофаминергических нейронов сопровождалось драматическим снижением способности животных к обучению и запоминанию. При этом, если гибель нейронов регистрировалась с 15-го или 30-го дня жизни мух, то наблюдаемое резкое снижение способности к обучению и запоминанию по сравнению с контро- 
лем, указывает на более ранние события, связанные, на наш взгляд, с потерей синапсов. В этой связи надо отметить, что проведенные post mortem исследования показали, что изменению уровня ChAT в мозге больных БА предшествует гибель синапсов (Tiraboschi et al., 2000). Хотя в настоящее время клеточные функции APP остаются не вполне понятными, роль этого белка в образовании и поддержании синапсов не подвергается сомнению (Müller, Zheng, 2012). Мы предполагаем, что в основе наблюдаемых нами нейродегенеративных изменений лежит нарушение синаптической функции APP. Полученные нами результаты показывают, что нейродегенерация в мозге животных и уменьшение способности к обучению и запоминанию обусловлены экспрессией именно полноразмерного гена $A P P$ или $A P P$ Sw. Хотя многочисленные исследования, проведенные на Drosophila melanogaster (Iijima-Ando, Iijima, 2010), показывают нейротоксичность А $\beta$, мы не наблюдали значительного вклада его образования в усиление наблюдаемой нейропатологии, что может быть связано с умеренным образованием $\mathrm{A} \beta$ в используемой нами модели.

Представленные результаты позволяют взглянуть на развитие нейродегенерации при БА с точки зрения возможных аномальных функций мутантного APP. При экспрессии APP человека в нервных клетках Drosophila его продукт транспортируется в пресинаптический терминал нейронов и постсинаптические участки нейромышечных контактов (Yagi et al., 2000), конкурируя с Appl, гомологом APP в Drosophila melanogaster. Надо отметить, что Appl экспрессируется в основном в нервной системе и играет ключевую роль в формировании и поддержании синапсов у Drosophila. Выключение гена Appl не приводило к летальному эффекту, но вызывало значительное изменение поведенческих реакций (Luo et al., 1992), а также уменьшение числа и размеров синаптических бутонов нейромышечных контактов личинок Drosophila, в то время как его гиперэкспрессия приводила к увеличению числа и размеров синаптических бутонов (Torroja et al., 1999). Так как APP и Appl, являются интегральной частью цитоскелета клетки [Li et al., 2004], вполне вероятно, что мутантный $A P P$ или гиперэкспрессия $A P P$ дикого типа приводят к нарушению целостности цитоскелета, дегенерации синаптического компартмента и, как следствие, уменьшению числа нормальных синапсов. Кроме того, конкуренция Appl и АРP может подавлять регуляцию экспрессии синаптических генов через протеинкиназа G-зависимый механизм (Claasen et al., 2009). В то же время фрагменты протеолитического расщепления АРP также могут влиять на транскрипционную активность синаптических генов Drosophila (Müller et al., 2007). Так, цитоплазматический фрагмент APP (APP intracellular domain, AICD), генерируемый при протеолизе APP $\gamma$-секретазой может транслоцироваться в ядро, регулировать генную экс- прессию, синаптическую пластичность и память (Сао, Sudhof, 2001). Как регулятор транскрипции AICD влияет на ремоделирование хроматина посредством связывания с ацетилтрансферазой гистонов Тір60 (Сао, Sudhof, 2001, 2004). Примечательно, что трансгенные мыши, с гиперэкспрессией AICD, проявляли нейропато логические черты, характерные для БА, включая гиперфосфорилирование тау, нейродегенерацию, нарушение памяти (Ghosal et al. 2009), что указывает на важность рассмотрения других продуктов АРР в патогенезе БА.

Работа выполнена при финансовой поддержке Российского фонда фундаментальных исследований (проекты 09-04-00647-а).

\section{ЛИТЕРАТУРА}

1. Bonda J.D., Wang X., Gustaw-Rothenberg K. et al., 2009. Mitochondrial Drugs for Alzheimer Disease // Pharmaceuticals. Vol. 2. P. 287-298.

2. Botella J., Bayersdorfer F., Schneuwly S., 2008. Superoxide dismutase overexpression protects dopaminergic neurons in a Drosophila model of Parkinson's disease // Neurobiology of Desease. Vol. 30. P. 7573.

3. Brand A.H., Perrimon N., 1993. Targeted gene expression as a means of altering cell fates and generating dominant phenotypes//Development. Vol. 118. P. 401-415.

4. Burns J.M., Galvin J.E., Roe C.M. et al., 2005. The pathology of the substantia nigra in Alzheimer disease with extrapyramidal signs // Neurology. Vol. 64. P. 1397-1403.

5. Cao X., Südhof T.C., 2001. A transcriptionally [correction of transcriptively] active complex of APP with Fe65 and histone acetyltransferase Tip60//Science. Vol. 293. P. 115-120.

6. Cao X., Südhof T.C., 2004. Dissection of amyloid-beta precursor protein-dependent transcriptional transactivation // J. Biol. Chem. Vol. 279. P. 24601-24611.

7. Chen K.H., Reese E.A., Kim H-W. et al., 2011. Disturbed Neurotransmitter Transporter Expression in Alzheimer Disease Brain//J. Alzheimers Dis. Vol. 26. P. 755-766.

8. Claasen A.M., Guévremont D., Mason-Parker S.E. et al., 2009. Secreted amyloid precursor protein-alpha upregulates synaptic protein synthesis by a protein kinase G-dependent mechanism.//Neur. Lett. Vol. 460. P. 92-96.

9. Davies P., 1979. Neurotransmitter-related enzymes in senile dementia of Alzheimer type // Brain Res. Vol. 171. P. 319-327.

10. Exley R., McIntosh J.M., Marks M.J. et al., 2012. Striatal $\alpha 5$ nicotinic receptor subunit regulates dopamine transmission in dorsal striatum//J. Neurosci. Vol. 32. P. 2352-2356. 
11. Francis P.T., Palmer A.M., Snape M., Wilcock G.K., 1999. The cholinergic hypothesis of Alzheimer's disease: a review of progress // J. Neurol. Neurosurg. Psychiatry. Vol. 66. P. 137-147.

12. Ghosal K., Vogt D.L., Liang M. et al., 2009. Alzheimer's disease-like pathological features in transgenic mice expressing the APP intracellular domain // Proc. Natl. Acad. Sci. USA. Vol. 106. P. 18367-18372.

13. Guan Z.Z., Zhang X., Ravid R., Nordberg A., 2000. Decreased protein levels of nicotinic receptor subunits in the hippocampus and temporal cortex of patients with $\mathrm{Al}$ zheimer's disease//J. Neurochem. Vol. 74. P. 237-243.

14. Hardy J., Selkoe D.J., 2002. The amyloid hypothesis of Alzheimer's disease: progress and problems on the road to therapeutics. An updated summary of the amyloid hypothesis // Science. Vol. 297. P. 353-356.

15. Iijima-Ando K., Iijima K., 2010. Transgenic Drosophila models of Alzheimer's disease and tauopathies // Brain Struct. Funct. Vol. 214. P. 245-262.

16. Kar S., Slowikowski S.P, Westaway D, Mount H.T., 2004. Interactions between $\beta$-amyloid and central cholinergic neurons: implications for Alzheimer's disease // J. Psychiatry Neurosci. Vol. 29. P. 427-468.

17. Kazee A.M., Cox C., Richfield E.K., 1995. Substantia nigra lesions in Alzheimer disease and normal aging // Alzheimer Dis. Assoc. Disord. Vol. 9. P. 61-67.

18. Kim H., Kim E., Lee J. et.al., 2003. C-terminal fragments of amyloid precursor protein exert neurotoxicity by inducing glycogen synthase kinase-3 $\beta$ expression. // The FASEB Journal. Vol. 17. P. 1951-1953.

19. Li Y., Liu T., Peng Y. et al., 2004. Specific functions of Drosophila amyloid precursor-like protein in the development of nervous system and nonneural tissues //J. Neurobiol. Vol. 61. P. 343-58.

20. Luo L., Tully T., White K., 1992. Human amyloid precursor protein ameliorates behavioral deficit of flies deleted for Appl gene // Neuron. Vol. 9. P. 595-605.

21. Mesulam M.M., Mufson E.J., Wainer B. H., Levey A.I., 1983. Central cholinergic pathways in the rat: an overview based on an alternative nomenclature (Ch1-Ch6) // Neuroscience. Vol. 10. P. 1185-1201.

22. Mohandas E., Rajmohan V., Raghunath B., 2009. Neurobiology of Alzheimer's disease // Indian J. Psychiatry. Vol. 51. P. 55-61.

23. Müller T., Concannon C. G., Ward M. W. et al. Modulation of gene expression and cytoskeletal dynamics by the amyloid precursor protein intracellular domain (AICD) // Biol. Cell. 2007. V. 18. P. 201-210.

24. Müller U.C., Zheng H., 2012. Physiological Functions of APP Family Proteins // Cold Spring Harb Perspect Med. Vol. 2: a006288.

25. Perez S.E., Lazarov O., Koprich J.B. et al., 2005. Nigrostriatal Dysfunction in Familial Alzheimer's DiseaseLinked APPswe/PS1 -E9 Transgenic Mice // The Journal of Neuroscience Vol. 25. P. 10220 - 10229.
26. Perry E.K., Morris C.M., Court J.A. et al., 1995. Alteration in nicotine binding sites in Parkinson's disease, Lewy body dementia and Alzheimer's disease: possible index of early neuropathology//Neurosci. Vol. 64. P. 385-395.

27. Pimplikar S.W., Nixon R.A., Robakis N.K. et al., 2010. Amyloid-independent mechanisms in Alzheimer's disease pathogenesis//J. Neurosci. Vol. 30. P. 14946-14954.

28. Sarantseva S., Timoshenko S., Bolshakova O. et al., 2009. Apolipoprotein E-Mimetics Inhibit Neurodegeneration and Restore Cognitive Functions in a Transgenic Drosophila Model of Alzheimer's Disease // PloS One. Vol. 4. e8191.

29. Saura C.A., Choi S.-U., Beglopoulos V. et al. 2004. Loss of presenilin function causes impairments of memory and synaptic plasticity followed by age-dependent neurodegeneration // Neuron. Vol. 42. P. 23-36.

30. Schaeffer E.L., Gattaz W.F., 2008 Cholinergic and glutamatergic alterations beginning at the early stages of Alzheimer disease: participation of the phospholipase A2 enzyme // Psychopharmacology. Vol. 198. P. 1-27.

31. Stokin G.B., Almenar-Queralt A., Gunawardena S. et al., 2008. Amyloid precursor protein-induced axonopathies are independent of amyloid-beta peptides // Hum. Mol. Genet. Vol. 17. P. 3474-3486.

32. Słomnicki L.P., Leśniak W., 2008. A putative role of the Amyloid Precursor Protein Intracellular Domain (AICD) in transcription // Acta Neurobiol. Exp (Wars). Vol. 68. P. 219-228.

33. Sun C., Ou X., Farley J.M., Stockmeier C. et al., 2012. Allopregnanolone Increases the Number of Dopaminergic Neurons in Substantia Nigra of a Triple Transgenic Mouse Model of Alzheimer's Disease // Curr. Alzheimer Res. Vol. 9. P. 473-480.

34. Thinakaran G., KooH.E., 2008. Amyloid Precursor Protein: Trafficking, Processing and Function // J. Biol. Chem. Vol. 283. P. 296-304.

35. Tiraboschi P., Hansen L.A., Alford M. et al., 2000. The decline in synapses and cholinergic activity is asynchronous in Alzheimer's disease//Neurology. Vol. 55. P. 1278-1283.

36. Torroja L., Packard M., Gorczyca M. et al., 1999. Drosophila b-Amyloid Precursor Protein homolog promotes synapse differentiation at the neuromuscular junction // J. Neurosci. Vol. 15. P. 7793-7803.

37. Tully T., Quinn W., 1985. Classical conditioning and retention in normal and mutant Drosophila melanogaster // Journal of Comparative Physiology. Vol.P. 263-277.

38. Walsh D.M., Selkoe D.J., 2004. Deciphering the molecular basis of memory failure in Alzheimer's disease // Neuron. Vol. 44. P. 181-193.

39. Whitehouse R.J., Price D.L., Struble R. G. et al., 1982. Alzheimer's disease and senile dementia: loss of neurons in the basal forebrain//Science. Vol. 215. P. 1237-1239.

40. Yagi Y., Tomita S., Nakamura M. et al., 2000. Overexpression of human amyloid precursor protein in Drosophila //Mol. Cell. Biol. Res. Comm. Vol. 157. P. 263-277. 


\section{THE EFFECTS OF OVEREXPRESSION OF HUMAN APP ON CHOLINERGIC AND DOPAMINERGIC NEURONS OF BRAIN OF DROSOPHILA MELANOGASTER}

Bolshakova O.I., Zhuk A.A., Rodin D.I., Kislik G.A., Sarantseva S.V.

8) SUMMARY: The influence of $A P P$ overexpression on cholinergic and dopaminergic neuronal populations was investigated. The number of cholinergic neurons, which was the same in the control and $A P P$ expressing young flies, decreased in the $A P P$ expressing flies with age. The number of dopaminergic neurons in $A P P$ expressing flies was significantly reduced after the 15 th day. Neurodegeneration was followed by the deficit of memory and learning abilities of the flies with APP expression as well as the flies with amyloid-beta-peptide production.

KEY WORDS: Alzheimer's disease; Drosophila melanogaster; neurodegeneration; cholinergic neurons; dopaminergic neurons; amyloid beta peptide

\section{(8) Информация об авторах}

Большакова Ольга Игоревна - научный сотрудник. Федеральное государственное бюджетное учреждение Петербургский институт ядерной физики им. Б. П. Константинова. 188300, Ленинградская обл, Гатчина, Орлова роща. E-mail: olya99991@yandex.ru.

Жук Анна Александровна - старший лаборант. Федеральное государственное бюджетное учреждение Петербургский институт ядерной физики им. Б. П. Константинова. 188300, Ленинградская обл, Гатчина, Орлова роща.

E-mail: azhukomi@mail.ru.

Родин Дмитрий Игоревич - младший научный сотрудник. Федераль ное государственное бюджетное учреждение Петербургский институт ядерной физики им. Б. П. Константинова. 188300, Ленинградская обл, Гатчина, Орлова роща.

E-mail:nomadkml@me.com.

Кислик Галина Алексеевна - младший научный сотрудник. Федеральное государственное бюджетное учреждение Петербургский институт ядерной физики им. Б. П. Константинова. 188300, Ленинградская обл, Гатчина, Орлова роща.

E-mail: kislikgalina@hotmail.com

Саранцева Светлана Владимировна - руководитель лаборатории, к. б. н. Федеральное государственное бюджетное учреждение Петербургский институт ядерной физики им. Б. П. Константинова. 188300 , Ленинградская обл, Гатчина, Орлова роща

E-mail: svesar1@yandex.ru
Bolshakova Olga Igorevna - research associate. B. P. Konstantinov Petersburg Nuclear Physics Institute. Gatchina, Leningrad district 188300, Russia. E-mail: olya99991@yandex.ru.

Zhuk Anna Aleksandrovna - senior technician. B.P. Konstantinov Petersburg Nuclear Physics Institute. Gatchina, Leningrad district 188300, Russia. E-mail: azhukomi@mail.ru.

Rodin Dmitriy Igorevich - Junior Researcher . B.P. Konstantinov Petersburg Nuclear Physics Institute. Gatchina, Leningrad district 188300, Russia. E-mail: nomadkml@me.com

Kislik Galina Alekseevna - Junior Researcher . B.P. Konstantinov Petersburg Nuclear Physics Institute. Gatchina, Leningrad district 188300, Russia.

E-mail: kislikgalina@hotmail.com

Sarantseva Svetlana Vladimirovna - Head of Laboratory, Ph.D. B.P. Konstantinov Petersburg Nuclear Physics Institute. Gatchina, Leningrad district 188300, Russia.

E-mail: svesar1@yandex.ru 